\title{
Molecular characterization of two natural hybrids from the Iberian Peninsula: Ranunculus $\times$ luizetii and $R . \times$ peredae (Ranunculaceae)
}

\author{
${\text { Eduardo } \text { Cires }^{1 *} \text {, Candela Cuesta }}^{2,3}$ \& José Antonio Fernández Prieto ${ }^{1}$ \\ ${ }^{1}$ Área de Botánica. Universidad de Oviedo, Departamento de Biología de Organismos y Sistemas, Catedrático Rodrigo Uría \\ s/n, 33071 Oviedo, Spain; e-mail: cireseduardo@gmail.com \\ ${ }^{2}$ Área de Fisiología Vegetal. Universidad de Oviedo, Departamento de Biología de Organismos y Sistemas, Catedrático \\ Rodrigo Uría s/n, 33071 Oviedo, Spain \\ ${ }^{3}$ Department of Plant Systems Biology, VIB, Technologiepark 927, 9052 Ghent, Belgium
}

\begin{abstract}
Two nothospecies, Ranunculus $\times$ luizetii and $R . \times$ peredae (Ranunculaceae), were analyzed and discussed. For this purpose, Amplified Fragment Length Polymorphism (AFLP) markers, nuclear rDNA sequences (ITS1, 5.8S and ITS2) and pollen viability were conducted. The profiles of these hybrid samples were compared to their putative progenitors. Several additive polymorphic sites detected in the ITS sequences of the hybrid samples $(R . \times$ luizetii and $R$. $\times$ peredae $)$ also confirmed their derived origins from ribotypes of their parental taxa ( $R$. parnassiifolius subsp. parnassiifolius $\times R$. pyrenaeus; $R$. amplexicaulis $\times R$. cabrerensis subsp. cabrerensis, respectively). Despite the lack of exclusive AFLP markers reported in both hybrids, presumably due to effects of introgression, the concerted evolution of many rDNA polymorphisms towards either of the parental ribotypes indicated their ancient origin. Pollen fertility estimation in $R$. $\times$ luizetii presented a mean value of $60.58 \%$, which showed that hybrid samples are well established and fertile. However, a larger difference was observed in $R$. × peredae, where the mean value of pollen fertility was very low $(18.91 \%)$.
\end{abstract}

Key words: Ranunculus amplexicaulis; R. cabrerensis; R. parnassiifolius; R. pyrenaeus; AFLP; hybrid; introgression; ITS; pollen fertility

\section{Introduction}

Hybridisation is a well known natural phenomenon and an important mechanism of evolution in plants (e.g. Rieseberg 1995; Arnold 1997; Wissemann 2005). However, the frequency of spontaneous hybridization is not universal and differs between plant families and genera, as demonstrated in multiple biosystematics floras (Ellstrand et al. 1996). In natural habitats, many spontaneous hybrids have been found in the family Ranunculaceae, especially between species of the genus Ranunculus (e.g. Hüber 1988). The extraordinarily large hybridization potential of the buttercups has often been considered a result of the sympatric occurrence of different taxa, the overlap in flowering periods, and the close phylogenetic relationships of the parental taxa involved in each hybridization event. Most of the hybrid combinations among Ranunculus taxa are easily identified in the field, as show intermediate morphologies compared to their sympatrically parents.

Two hybrid taxa have been described in the section Ranuncella of the genus Ranunculus: $R . \times$ luizetii Rouy (R. parnassiifolius subsp. parnassiifolius L. $\times R$. pyrenaeus L.) from the Pyrenees (Rouy 1893) and $R$. $\times$ peredae M.Laínz (R. amplexicaulis L. $\times$ R. cabrerensis subsp. cabrerensis Rothm.) from the Cantabrian Mountains (Laínz 1964; Cires \& Fernández Prieto 2012). The occurrences of hybridization among those species of Ranunculus have been suggested on the basis on morphological intermediacy of some individuals found in the same habitat as their putative progenitors. In spite of the molecular techniques, such as Amplified Fragment Length Polymorphism (AFLP) or Internal Transcribed Spacers of the ribosomal DNA (ITS), that have made the detection of hybridization increasingly easier and have many advantages over morphological data to reveal hybrids individuals (Allendorf et al. 2001), only a few taxa of the genus Ranunculus have been confirmed by molecular means (e.g. Hörandl et al. 2009).

In the present work, the hypothesis that morphological intermediate individuals have derived from natural hybridization in $R . \times$ luizetii and $R$. × peredae were tested. For this purpose: 1) fertility of presumable hybrids was estimated, 2) nuclear rDNA (ITS) sequences were analysed to verify additive profiles from both putative parents, and finally 3) AFLP analyses were used to assess the relationship and genetic distinction or its lack between the putative hybrids and their progenitors.

\footnotetext{
* Corresponding author
} 


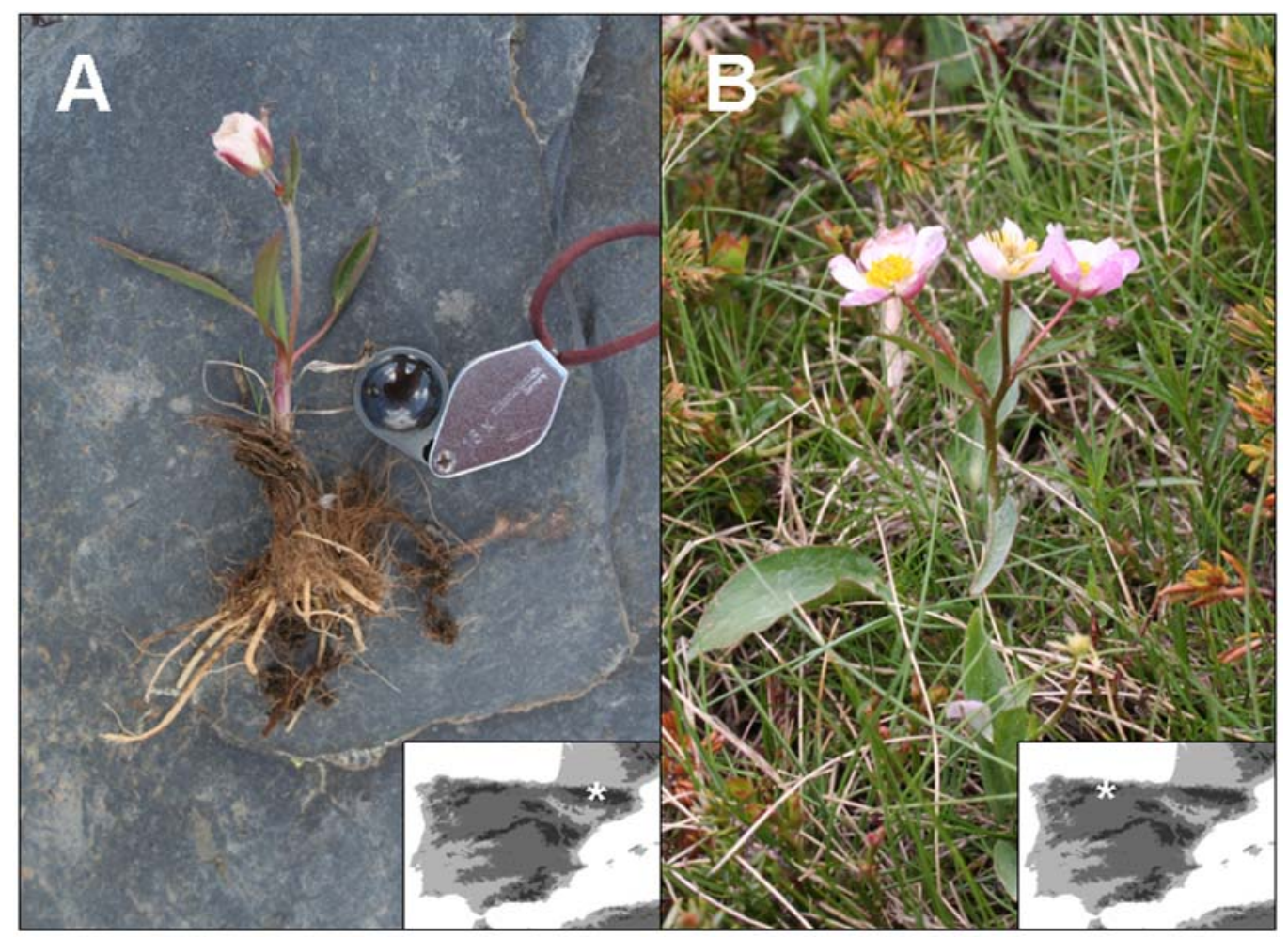

Fig. 1. Morphological appearance and geographical distribution of Ranunculus $\times$ luizetii and $R . \times$ peredae.

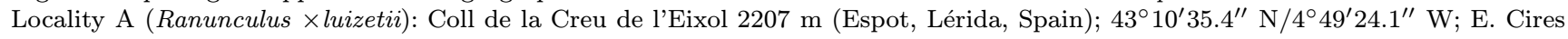
\& J.A. Fernández Prieto; 31975 FCO.

Locality B (Ranunculus × peredae): Portillo de las Yeguas, San Glorio $2095 \mathrm{~m}$ (Vega de Liébana, Cantabria, Spain); $43^{\circ} 3^{\prime} 15.3^{\prime \prime}$ $\mathrm{N} / 4^{\circ} 44^{\prime} 21.2^{\prime \prime}$ W; A. Bueno \& E. Cires 31976 FCO.

\section{Material and methods}

Plant material and DNA isolation

Fresh leaves from the specimens morphologically identified a priori as putative hybrids Ranunculus $\times$ luizetii, $R . \times$ peredae and presumable parental species were sampled from two localities in the Iberian Peninsula (Fig. 1). Hybrid identification was based on the combination of parental morphological characters (Fig. 1). Vouchers specimens were deposited in the Herbarium of the University of Oviedo (FCO). Samples for molecular analyses were dried in silica gel and stored prior to DNA isolation. DNA isolation was carried out using the DNeasy Plant Minikit (Qiagen) following the manufacturer's instructions.

\section{AFLP analysis}

AFLP analysis followed the protocol from Vos et al. (1995) with minor modifications. DNA was isolated from silica geldried material collected in the field, digested with restriction enzymes EcoRI and $M s e \mathrm{I}$ for $2 \mathrm{~h}$ at $37^{\circ} \mathrm{C}$ and simultaneously ligated to double-stranded EcoRI and MseI adapters. Preselective amplifications were performed using primers with a one base pair extension. In a second selective amplification, the number of fragments was further reduced by primers with a three base pair extension. For this second amplification, 9 primer combinations were used: EcoRI-AAC / MseICAT; EcoRI-ACG / MseI-CAT; EcoRI-ACT / MseI-CAT; EcoRI-AAC / MseI-CTT; EcoRI-ACG / MseI-CTT; EcoRIACT / MseI-CTT; EcoRI-AAC / MseI-CCAC; EcoRI-ACG / MseI-CCAC and EcoRI-ACT / MseI-CCAC. Selective amplification products were sent to the Sequencing Services of the University of Oviedo for fragment analysis: samples were run on an automated DNA sequencer (ABI PRISM ${ }^{\circledR} 3100$,
Applied Biosystems) with an internal size standard GeneScan 500 (ROX ${ }^{\mathrm{TM}}$, Applied Biosystems); and raw AFLP data were collected and sized using the Genemapper 4.0 software (Applied Biosystems). AFLP fragments were scored as present (1) or absent (0), and used as a raw data matrix Principal coordinates analysis ( $\mathrm{PCoA}$ ) was performed on the Dice similarity matrix using Past 1.89 (Hammer et al. 2001) to visualize the genetic relationships among all individual AFLP phenotypes.

\section{Nuclear rDNA (ITS) amplification and sequencing}

The ITS region (ITS1, 5.8S and ITS2) was amplified as a single piece with primers 17SE and 26SE (Sun et al. 1994; Hörandl et al. 2005). Amplification of selected regions was carried out in $25 \mu \mathrm{L}$ of reaction mixture (25 ng template DNA, $2.5 \mu \mathrm{L}$ of $10 \times$ PCR buffer, $2.5 \mathrm{mM} \mathrm{MgCl}_{2}, 0.2 \mathrm{mM}$ dNTPs, $0.08 \mu \mathrm{M}$ of each primer and $1 \mathrm{U}$ of Taq DNA polymerase, Invitrogen), in an Eppendorf Mastercycler Epgradient $\mathrm{S}$ (Westbury, NY). After 5 min pre-treatment at $94^{\circ} \mathrm{C}, \mathrm{PCR}$ conditions were: 40 cycles of $1 \mathrm{~min}$ at $94^{\circ} \mathrm{C}$, $1 \mathrm{~min}$ at $56^{\circ} \mathrm{C}, 1 \mathrm{~min}$ at $72^{\circ} \mathrm{C}$; plus a final extension of $10 \mathrm{~min}$ at $72^{\circ} \mathrm{C}$. All chromatograms were visually examined to correct possible misinterpretations of the computational routine. Sequenced data were assembled and edited using ClustalW v.1.83 algorithm implemented in Geneious Pro 5.3 (Biomatters, Auckland, New Zealand). IUPAC (International Union of Pure and Applied Chemistry) symbols were used to represent nucleotide ambiguities. All nuclear and plastid sequences have been deposited in GenBank (JQ801610-JQ801633). Phylogenetic trees were constructed using the MEGA v. 5.0 (Tamura et al. 2011) packages with p-distances and the neighbour-joining (NJ) method (Saitou 
A

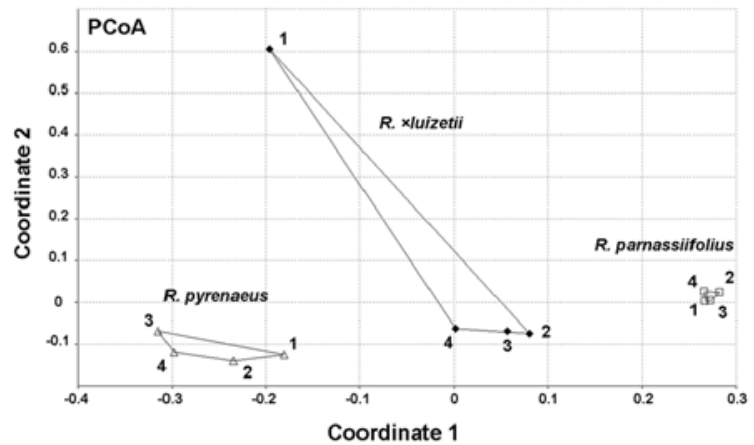

NJ

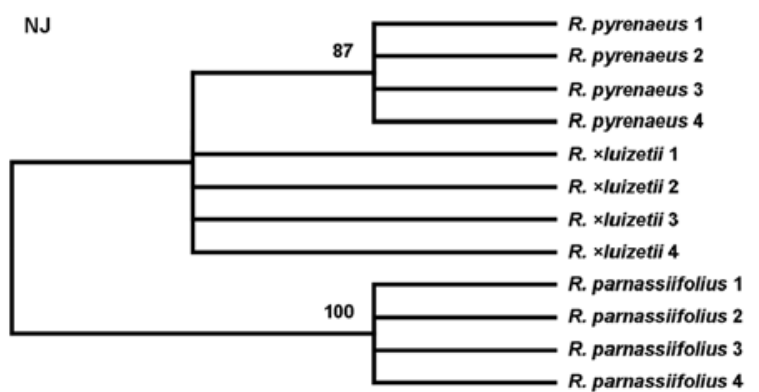

B

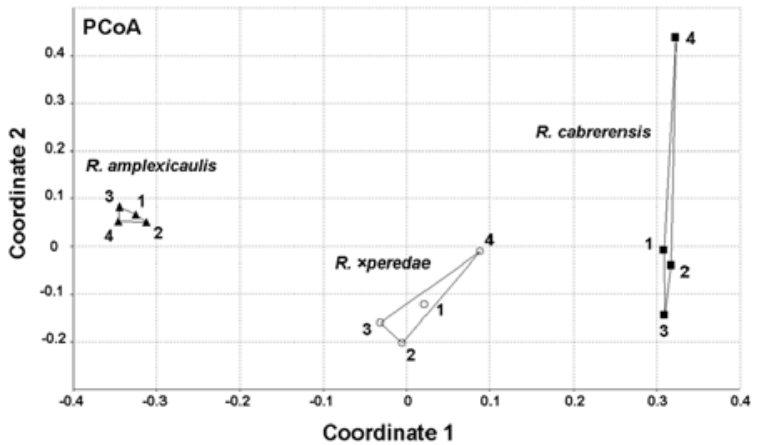

NJ

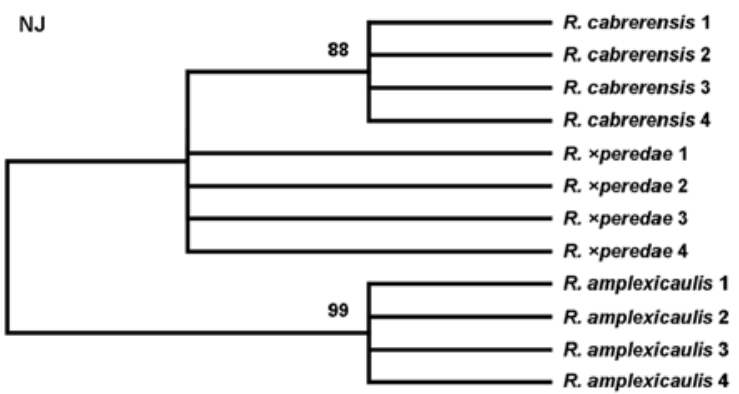

Fig. 2. Principal coordinates analysis (PCoA) from AFLP data and neighbor-joining (NJ) tree derived from ITS sequences for the hybrids Ranunculus $\times$ luizetii and $R . \times$ peredae and their presumable parental species. A) Pyrenean population of $R$. $\times$ luizetii (filled diamonds: $\downarrow$ ), $R$. parnassiifolius (open squares: $\square$ ) and $R$. pyrenaeus (open triangles: $\Delta$ ). B) Cantabrian population of $R$. $\times$ peredae (open circles: $\circ$ ), R. amplexicaulis (filled triangles: $\mathbf{\Delta}$ ) and $R$. cabrerensis (filled squares: $\mathbf{\square})$.

\& Nei 1987). Bootstrap values were calculated from 1000 replications using the MEGA program.

\section{Pollen stainability}

Pollen was obtained from several anthers from different flowers of a single plant. Pollen was cleaned and dried on the slide by the addition of ethyl alcohol (70 and 96\%). Subsequently, the pollen slides were prepared according to the method of Wodehouse (Wodehouse 1935), using methylene blue dye. The preparation was then covered with a cover slip, and after that the slides were examined under a light microscope. Pollen fertility, indicated by pollen stainability, was estimated by counting 500 mature pollen grains: darkly stained pollen grains were recorded as fertile and viable, meanwhile unstained or very lightly stained ones were considered as sterile or non-viable. Pollen fertility was calculated by dividing the number of viable pollen grains by the total number of grains counted in the field of view, and averaging them for all plants in that species. Then, pollen viability was expressed as percentage pollen fertility in each plant species, and also pollen fertility range was recorded by taking the lowest and highest values of pollen viability percentage.

\section{Results}

PCoA analyses based on AFLP data (Fig. 2A-B) revealed the genetic intermediateness of the hybrid samples $(R . \times$ luizetii and $R . \times$ peredae) with respect to those of the parental taxa and the samples analysed clustered into three separate groups in each of the hybrid populations. In the case of $R$. $\times$ luizetii population, the first and second axes explained 33.16 and $23.33 \%$ of the total variation, respectively $(13.71 \%$ in the case of axis 3, not shown). On the other hand, the first and second axes of $R . \times$ peredae population explained 41.49 and $15.35 \%$ of the total variation respectively (axis 3 explained $10.78 \%$, not shown). Concerning to the nuclear rDNA (ITS), the main differentiating characters between the hybrid and its parents are summarized in Table 1 . The hybrid accessions of $R$. × luizetii showed additive polymorphisms at the 3 sites where both parents differed in sequence meanwhile the hybrid $R . \times$ peredae showed 2 additive polymorphic sites. Pollen fertility results are given in Table 2 .

\section{Discussion}

Natural hybridization occurs widely in plants and has a significant role in their evolution (Arnold 1997) with important consequences in conservation biology (Genovart 2009). Our study has demonstrated the hybrid nature of Ranunculus $\times$ luizetii and $R . \times$ peredae collected from the Pyrenees and the Cantabrian Mountains, respectively. In both cases, the intermediacy of morphological characters and the additive patterns of AFLP bands in these hybrid samples allowed us to demonstrate hybridization events between the two presumed parents. The hybridization between these two taxa was also confirmed in our study through the analysis of ITS sequences that showed additive polymorphic sites as well as the assessment of pollen fertility. The absence of exclusive AFLP bands in the hybrid samples with respect to their parents indicates that these taxa were involved in the crosses that originated the hybrids and that the hybridization events likely occurred in relatively recent times. However, introgression effects seem the most likely explanation for this phenomenon be- 
Table 1. Summary of the nucleotide site variation of the Internal Transcribed Spacers (ITS1 and ITS2) in the hybrids Ranunculus $\times$ luizetii and $R$. × peredae and their presumable parental species. Additive polymorphic sites are denoted using IUPAC ambiguity symbols. For each sample, the GenBank accession number is indicated.

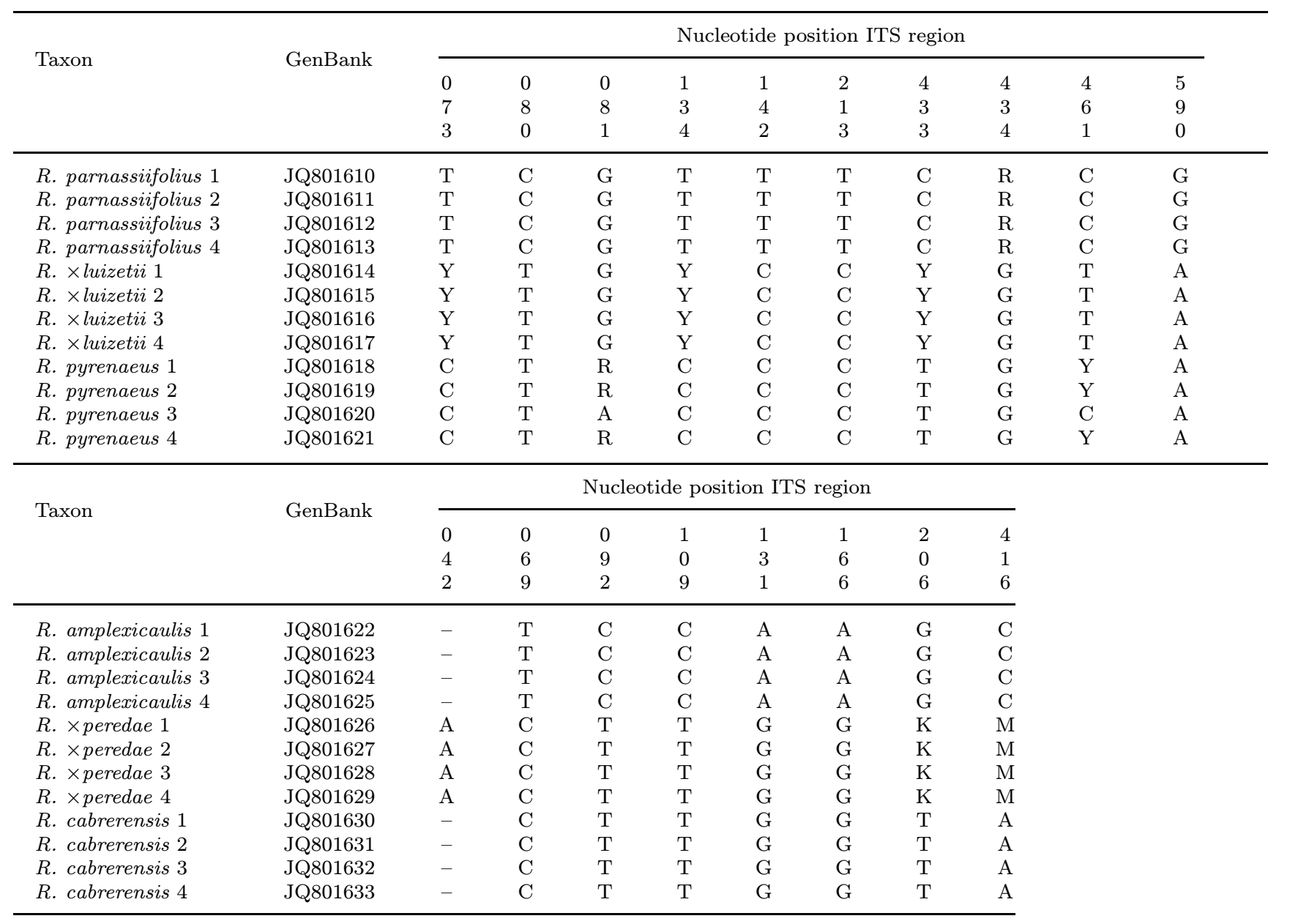

Table 2. Comparison of pollen fertility in the hybrids Ranunculus $\times$ luizetii and $R$. $\times$ peredae and their putative parental species. The values are given as range of values and means with standard deviation of the mean (S.D.). $n$ : number of examined plants.

\begin{tabular}{|c|c|c|c|}
\hline \multirow{2}{*}{ Taxa } & \multirow{2}{*}{$n$} & \multicolumn{2}{|c|}{ Pollen fertility percentage } \\
\hline & & Range & Mean \pm S.D. \\
\hline R. parnassiifolius & 6 & $33.20-95.05$ & $78.70 \pm 24.12$ \\
\hline R. $\times$ luizetii & 3 & $9.45-88.49$ & $60.58 \pm 44.34$ \\
\hline R. pyrenaeus & 4 & $40.78-93.04$ & $76.60 \pm 24.22$ \\
\hline R. amplexicaulis & 3 & $85.28-91.47$ & $88.69 \pm 3.14$ \\
\hline R. $\times$ peredae & 4 & $8.53-29.69$ & $18.91 \pm 11.36$ \\
\hline R. cabrerensis & 3 & $75.18-94.79$ & $87.64 \pm 10.90$ \\
\hline
\end{tabular}

cause if we consider nuclear rDNA sequences (ITS1, $5.8 \mathrm{~S}$ and ITS2), occur the expected biased concerted evolution of the rDNA sequences towards one of the parental genomes, characteristic of more ancient hybrids (Fuertes Aguilar et al. 1999; Nieto Feliner \& Rosselló 2007).

The Pyrenees and the Cantabrian Mountains have been recognized as a secondary contact zone for hybrid swarms of several plant species (Hewitt 1996, 2000; Lihová et al. 2007), however we should noted the scarcity of the hybrid individuals detected of $R$. $\times$ luizetii (around 20 individuals in the study population; without data about the number of populations in the Pyrenees) and $R$. × peredae (a single known population with about 7 individuals). Consequently, these hybrids should be considered as naturally very rare and included in National catalogues of endangered taxa and Red Lists. Despite this rarity, the conservation of the hybrids $R$. × luizetii and $R$. × peredae may not pose serious problems because they benefit from conservation policies devoted to its coexisting parent $R$. parnassiifolius subsp. parnassiifolius and $R$. cabrerensis subsp. cabrerensis.

\section{Acknowledgements}

We are grateful to María Ángeles Fernández Casado and María del Carmen Fernández-Carvajal for providing pollen analyses and Álvaro Bueno for helping with the sampling. The authors would like to thank the anonymous reviewers for their valuable comments and suggestions to improve the quality of the paper.

\section{References}

Allendorf F.W., Leary R.F., Spruell P. \& Wenburg J.K. 2001. The problems with hybrids: setting conservation guidelines. Trends Ecol. Evol. 16: 613-622. 
Arnold M.L. 1997. Natural hybridization and evolution. Oxford University Press, New York.

Cires E. \& Fernández Prieto J.A. 2012. The Iberian endemic species Ranunculus cabrerensis Rothm.: an intricate history in the Ranunculus parnassiifolius L. polyploid complex. Plant Syst. Evol. 298: 121-138.

Ellstrand N.C., Whitkus R. \& Rieseberg L. 1996. Distribution of spontaneous plant hybrids. Proc. Nat. Acad. Sci. USA 93: $5090-5093$.

Fuertes Aguilar J., Rosselló J.A. \& Nieto Feliner G. 1999. Nuclear ribosomal DNA (nrDNA) concerted evolution in natural and artificial hybrids of Armeria (Plumbaginaceae). Mol. Ecol. 8: 1341-1346.

Genovart M. 2009. Natural hybridization and conservation. Biodiversity Conserv. 18: 1435-1439.

Hammer $\varnothing$., Harper D.A.T. \& Ryan P.D. 2001. PAST: paleontological statistics software package for education and data analysis. Palaeontol. Electronica. 4(1): 1-9.

Hewitt G.M. 1996. Some genetic consequences of ice ages, and their role in divergence and speciation. Biol. J. Linn. Soc. 58: $247-276$.

Hewitt G.M. 2000. The genetic legacy of the Quaternary ice ages. Nature 405: 907-913.

Hörandl E., Greilhuber J., Klimova K., Paun O., Temsch E., Emadzade K. \& Hodálová I. 2009. Reticulate evolution and taxonomic concepts in the Ranunculus auricomus complex (Ranunculaceae): insights from morphological, karyological and molecular data. Taxon 58: 1194-1215.

Hörandl E., Paun O., Johansson J.T., Lehnebach C., Armstrong T., Chen L. \& Lockhart P. 2005. Phylogenetic relationships and evolutionary traits in Ranunculus s.l. (Ranunculaceae) inferred from ITS sequence analysis. Mol. Phylogenet. Evol. 36: $305-327$.

Hüber W. 1988. Natürliche Bastardierungen zwischen weissblühenden Ranunculus-Arten in den Alpen. Veröff. Geobot. Inst. ETH Zürich 100: 1-160.

Laínz M. 1964. Aportaciones al conocimiento de la Flora Cántabro-Astur, VIII. Bol. Inst. Estud. Asturianos, Supl. Ci. 10: $173-218$.
Lihová J., Kučera J., Perný M. \& Marhold K. 2007. Hybridization between two polyploid Cardamine (Brassicaceae) species in northwestern Spain: discordance between morphological and genetic variation patterns. Ann. Bot. 99: 1083-1096.

Nieto Feliner G. \& Rosselló J.A. 2007. Better the devil you know? Guidelines for insightful utilization of nrDNA ITS in specieslevel evolutionary studies in plants. Mol. Phylogenet. Evol. 44(2): 911-919.

Rieseberg L.H. 1995. The role of hybridization in evolution: old wine in new skins. Am. J. Bot. 82: 944-953.

Rouy G. 1893. Un Ranunculus hybride nouveau (R. luizeti). Bull. Soc. Bot. Fr. 40: 215.

Saitou N. \& Nei M. 1987. The neighbor-joining method: a new method for reconstructing phylogenetic trees. Mol. Phylogenet. Evol. 4: 406-425.

Sun Y., Skinner D.Z., Liang G.H. \& Hulbert S.H. 1994. Phylogenetic analysis of Sorghum and related taxa using internal transcribed spacers of nuclear ribosomal DNA. Theor. Appl. Genet. 89: 26-32.

Tamura K., Peterson D., Peterson N., Stecher G., Nei M. \& Kumar S. 2011. MEGA5: Molecular Evolutionary Genetics Analysis using maximum likelihood, evolutionary distance, and maximum parsimony methods. Mol. Biol. Evol. 28: 27312739 .

Vos P., Hogers R., Bleeker M., Reijand M., van de Lee T., Hornes M., Frijers A., Pot J., Peleman J., Kuiper M. \& Zabeau M. 1995. AFLP: a new technique for DNA fingerprinting. Nucleic Acids Res. 23: 4407-4414.

Wissemann V. 2005. Evolution by hybridization. The influence of reticulate evolution on the biosymmetrial patterns and processes in plants. Theory Bioscienc. 123(3): 223-233.

Wodehouse R.P. 1935. Pollen grains. Their Structure, Identification and Significance in Science and Medicine. McGraw-Hill, New York.

Received December 6, 2011

Accepted March 21, 2012 